\title{
Correction to: An enactive approach to pain: beyond the biopsychosocial model
}

\section{Peter Stilwell ${ }^{1}$ - Katherine Harman ${ }^{2}$}

Published online: 20 May 2019

(C) Springer Nature B.V. 2019

\section{Correction to: Phenomenology and the Cognitive Sciences}

\section{https://doi.org/10.1007/s11097-019-09624-7}

The original article unfortunately contains error in footnote 2 due to its double entry and interchanged figures 1 and 2 .

The correct figure 1 is shown below.

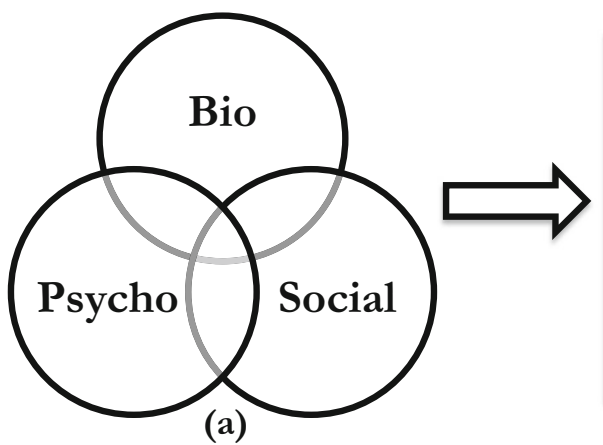

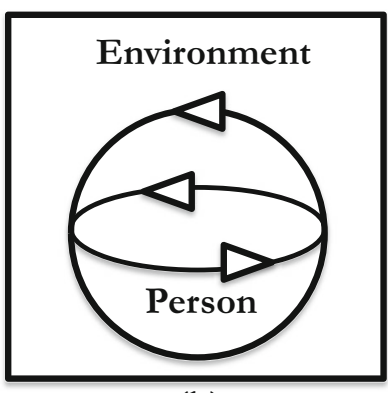

(b)

The online version of the original article can be found at https://doi.org/10.1007/s11097-019-09624-7

Peter Stilwell

peterstilwell@dal.ca

1 Faculty of Health, Dalhousie University, 5869 University Ave, PO Box 15000, Halifax, NS B3H 4R2, Canada

2 School of Physiotherapy, Faculty of Health, Dalhousie University, 5869 University Ave, PO Box 15000, Halifax, NS B3H 4R2, Canada 
The correct figure 2 is shown below.
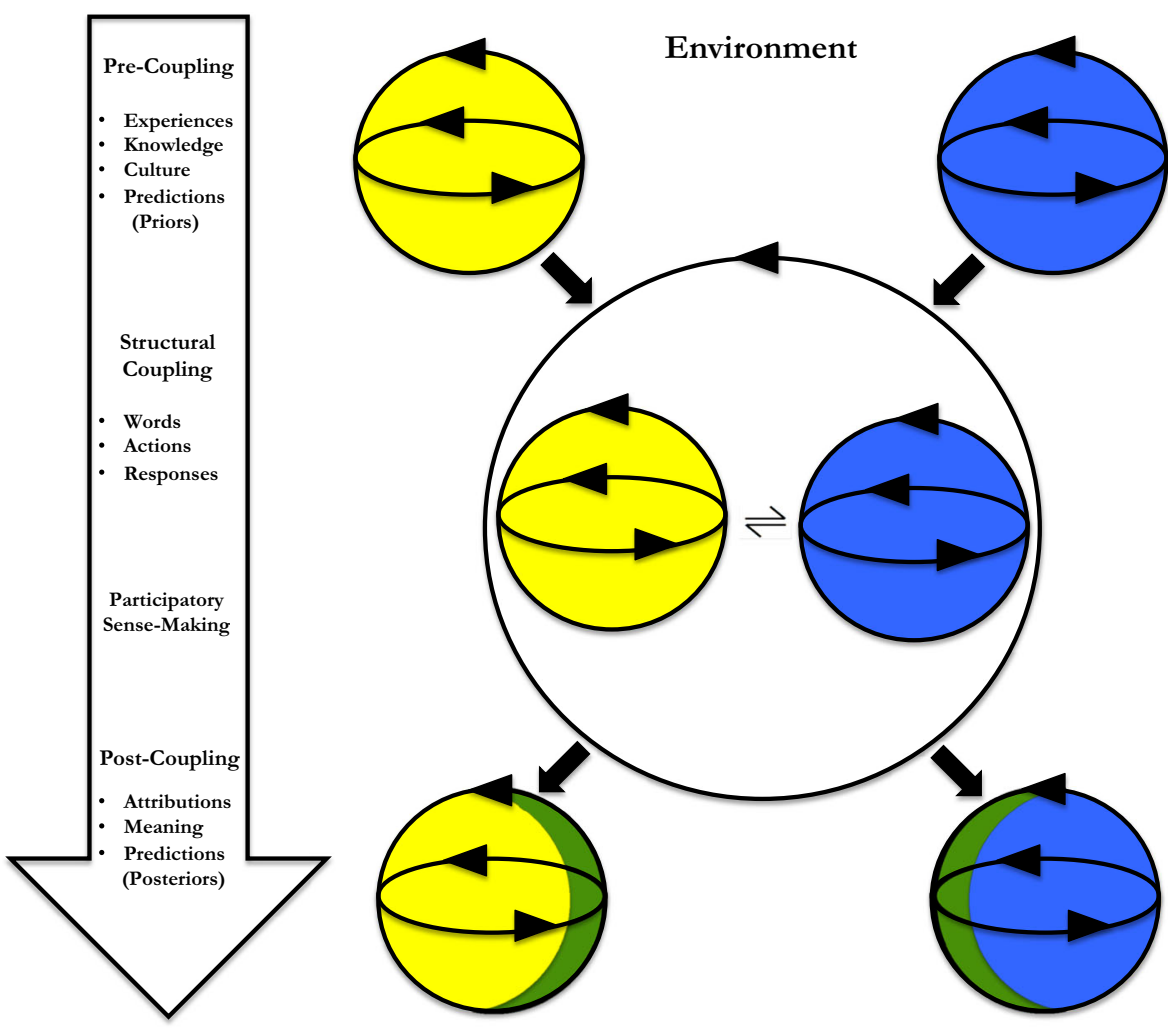

The original article has been corrected.

Publisher's note Springer Nature remains neutral with regard to jurisdictional claims in published maps and institutional affiliations. 